\title{
Space Remote Sensing and Detecting Systems of Oceangoing Ships
}

\section{Dimov Stojce Ilcev}

This paper introduces the implementation of space remote sensing and detecting systems of oceangoing ships as an alternative to the Radio - Automatic Identification System (R-AIS), Satellite - Automatic Identification System (S-AIS), Long Range Identification and Tracking (LRIT), and other current vessel tracking systems. In this paper will be not included a new project known as a Global Ship Tracking (GST) as an autonomous and discrete satellite network designed by the Space Science Centre (SSC) for research and postgraduate studies in Satellite Communication, Navigation and Surveillance (CNS) at Durban University of Technology (DUT). The ship detection from satellite remote sensing imagery system is a crucial application for

\section{KEY WORDS}

$\sim$ R-AIS

$\sim$ LRIT

$\sim$ GST

$\sim$ CNS

$\sim$ SSAR

$\sim$ VDS

$\sim$ SRSS

$\sim$ GEO

$\sim$ EOSS

$\sim$ SPS

$\sim$ UAV

$\sim$ SAR

$\sim$ LEO

$\sim$ MEO

$\sim$ TerraSAR-X

Durban University of Technogy, Space Science Center, Durban, South Africa e-mail: ilcev@dut.ac.za

doi: 10.7225/toms.v09.n02.004

This work is licensed under (cc) BY maritime safety and security, which includes among others ship tracking, detecting and traffic surveillance, oil spill detection service, and discharge control, sea pollution monitoring, sea ice monitoring service, and protection against illegal fisheries activities. The establishment of a modern sea surface and ships monitoring system needs enhancement of the Satellite Synthetic Aperture Radar (SSAR) that is here discussed as a modern observation infrastructure integrated with Ships Surveillance and Detecting via SSAR TerraSAR-X Spacecraft, Ships Surveillance and Detecting via SSAR Radarsat Spacecraft and Vessels Detecting System (VDS) via SSAR.

\section{INTRODUCTION}

Space remote sensing and detecting systems of oceangoing vessels are very important applications for their tracking, positioning and control. In fact, these applications have been developed and deployed as a potential systems implementing satellite remote sensing since its earliest days. Remote sensing images of the sea surface immediately reveal that ships can be seen from space with radar, optical sensors and especially via a Satellite Synthetic Aperture Radars (SSAR) onboard Geostationary Earth Orbit (GEO) spacecraft.

Space Remote Sensing System (SRSS) technology is providing surveillance and detecting of ships via SSAR, Ladar, Lidar, and Electro-Optical Space Surveillance (EOSS) using existing facilities of the GEO and Non-GEO satellite constellations including Stratospheric Platform Systems (SPS) or Unmanned Aerial Vehicles (UAV) stations. The oceanic surface vastness with all moving objects is globally observed by the remote sensing facilities, which space, ground and users segments are shown in Figure 1.

Therefore, in the development of satellite remote sensing technology, significant attention has been paid to the remote 
sensing images production of oceangoing ships from the space. Ship detection has been playing an important role in the field of remote sensing for a long time and can promote enhanced safety and security, port management, cargo transportation, and maritime Search and Rescue (SAR) solutions. Although many ship detection methods have been proposed in past, additional applications will be described in this context (Richards, 2009; Ilcev, 2016).

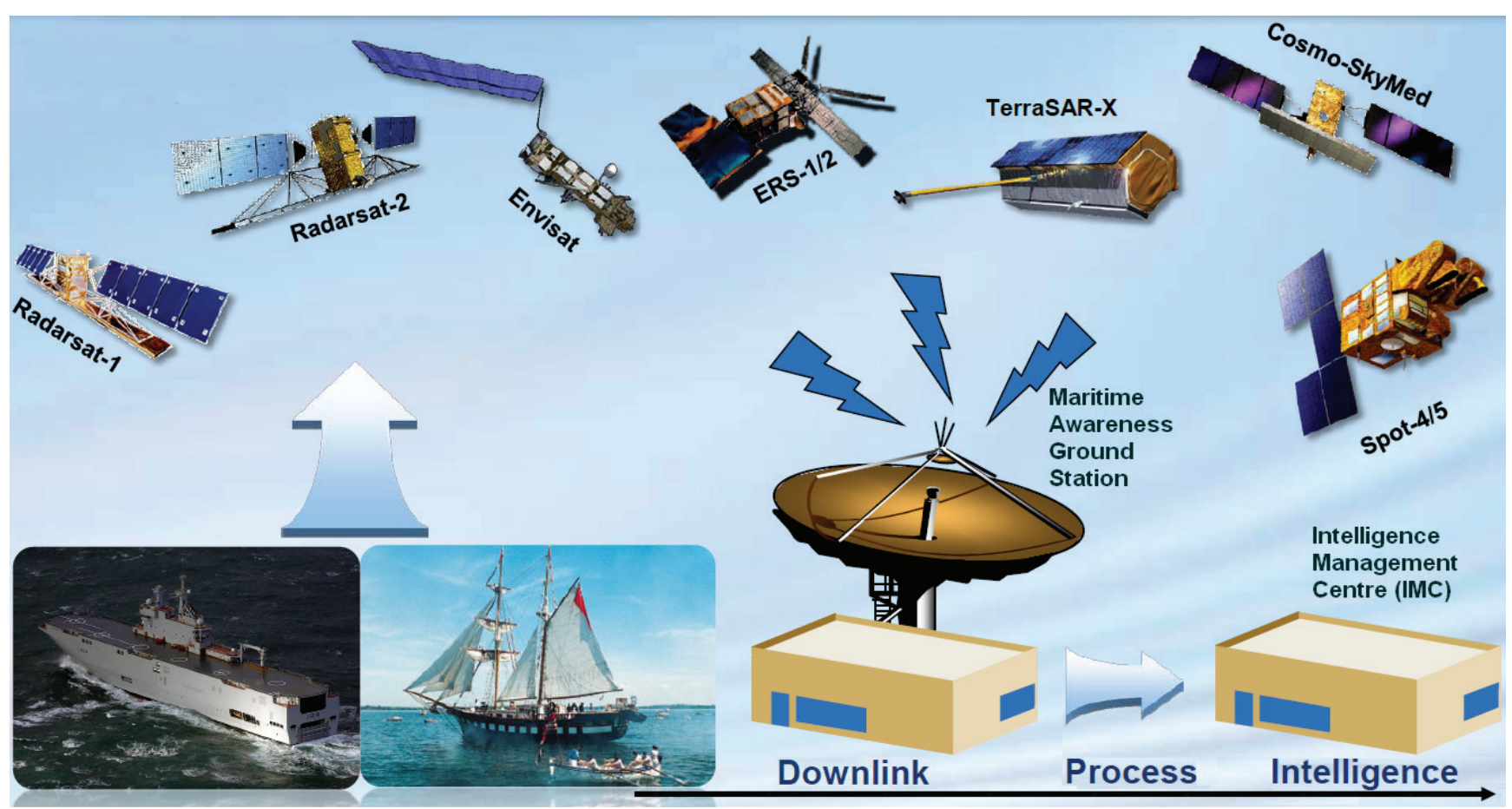

Figure 1.

Remote Sensing Solutions of Ships via Satellites - Source: Ilcev (2016).
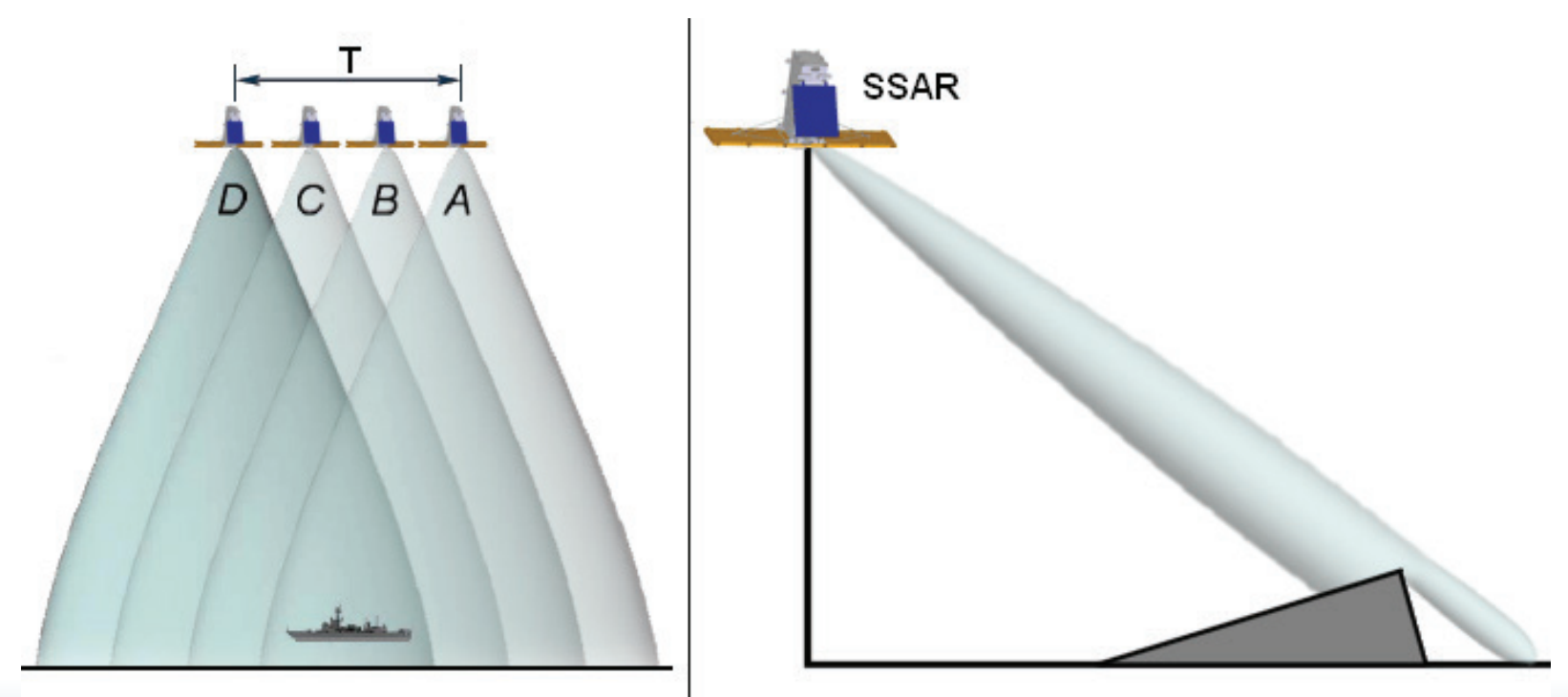

Figure 2.

Synthesized Expanding Beamwidth and Shadowing - Source: Wolff [3]. 


\section{SATELLITE SYNTHETIC APERTURE RADAR (SSAR) SENSORS}

Satellite Synthetic Aperture Radar (SSAR) as onboard spacecraft instruments or sensors can provide an efficient way of detecting ships in the open sea and through the wake and Doppler displacement measures their movement, speed, and direction. Request for maritime surveillance with new highresolution sensors has been increased, particularly in the field of the ships safety and security demand. Coastal surveillance systems are widely used but are limited in their coverage, while satellite imagery gives the possibility to overcome these limits. The possibility to provide efficient ship surveillance over wide regions and all weather conditions make SSAR a very well suited instrument for this application. Different satellite images at a variety of modes are available and can be selected depending on the extent of the area in order to monitor the different target sizes of interest. Repeated SSAR observation can contribute to a ships surveillance system, complementing information on routes from High Frequency (HF) coastal radars and shipboard R-AIS or S-AIS and other tracking systems.

The area accessible from SSAR generally increases with the elevation of the GEO satellites, while the map coverage rate is a more complicated function of platform velocity and beam agility. The Low Earth Orbit (LEO) satellite coverage is basically given by the ground velocity times of the relatively narrow swath width. The instantaneously accessible area will be limited to some hundreds of miles away from the sub-satellite point.

On the other extreme, the subsatellite point of GEO SSAR will move relatively slowly, while the area that can be accessed at any given time is very large, reaching thousands of miles from the subsatellite point. Thus, to effectively use the accessibility provided by a high vantage point, very large antennas with electronically steered array beams are required. Interestingly, Medium Earth Orbit (MEO) satellite constellations will enable powerful observational systems that provide large instantaneous reach and high mapping rates, while pushing technology less than alternative systems at higher altitudes. In Fact, using interferometric SSAR techniques that can reveal centimeterlevel (potentially sub-centimeter) surface displacements and frequent including targeted observations might be a key factor in developing such elusive applications as earthquake forecasting.

Although not strictly environmental measurements like the other parameters, ship signatures are found in ocean imagery made by many SSAR system operators. These significant signatures can provide information useful to environmental scientists, coastal and fishery managers, and law enforcement agencies. Characteristics such as high resolution (10 to $100 \mathrm{~m}$ ), sensitivity to small variations in surface roughness (on the order of centimeters), and especially the strong signal return from hard targets like ships make SSAR systems particularly adept at detecting vessels at sea. Ships may be detected via three main mechanisms: a) Identification of radar energy reflected directly from the vessel, b) Detecting of wake patterns and c) Identification of slicks on the ocean surface resulting from the release of engine or fish oils.

The SSAR application is coherent mostly spaceborne or airborne side-looking radar system which utilizes the flight path of the space platform to simulate an extremely large phase antenna or aperture electronically and that generates highresolution remote sensing imagery. The individual transmit/ receive Pulse Repetition Time (PRT) cycles are completed with the data from each cycle being stored electronically. The signal processing uses magnitude and phase of the received signals over successive pulses from elements of synthetic aperture radar.

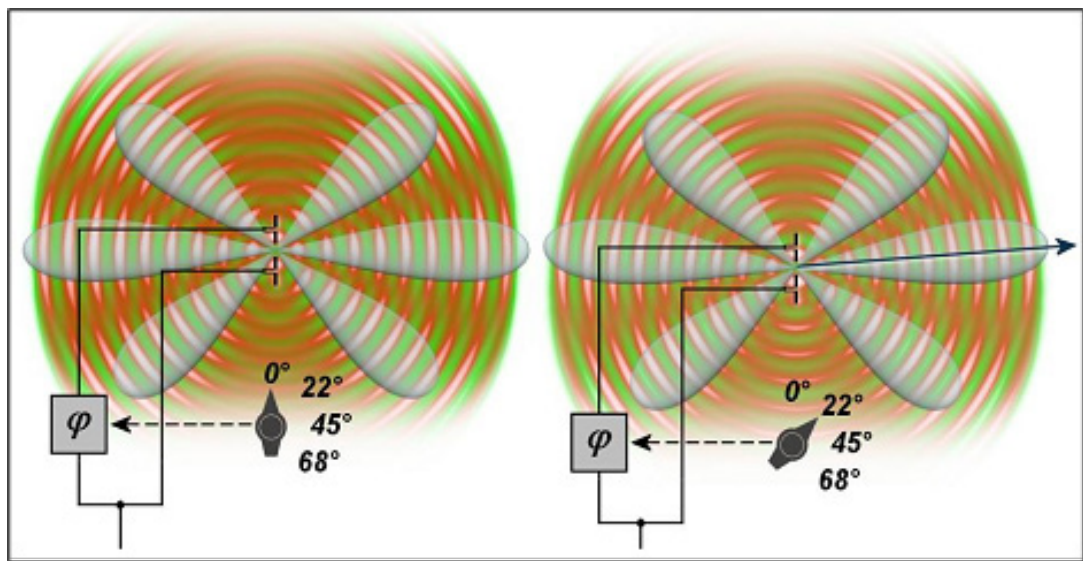

Figure 3.

SSAR Phase Array Antenna - Source: Wolff (2015). 
After a given number of cycles, the stored surveillance data is recombined (taking into account the Doppler effects inherent in the different transmitter to target geometry in each succeeding cycle) to create a high-resolution image of the land or sea surface being overflown. The SSAR-processor stores all the radar returned signals, as amplitudes and phases, for the time period T (Synthetic Length of SSAR coming from Imagine Phased Array) and from position $A$ to $D$, the Synthesized Expanding Beamwidth is shown in Figure 2 (Left). The accessible area of the SSAR radiating antenna sometimes decreases or even it suppresses, because a slope away from the radar illumination with an angle that is steeper than the sensor depression angle provokes radar shadows, which scenario is shown in Figure 2 (Right) (Ilcev, 2016; Wolff, 2015).

The shadowing effect increases with a greater incident or looks angle $\left(\theta_{0}\right)$, just as these shadows lengthen as the Sunsets. Thus, it should be also noted that the radar shadows of two objects of the same height are longer in the far range than in the near range. Shadow regions appear as dark (zero signal) with any changes due solely to system noise, sidelobes, and other effects normally of small importance.

Therefore, the SSAR system works similarly to a phased array, but the contrary to a large number of the parallel antenna elements of a phased array, SSAR uses one antenna in timemultiplex, which is shown in Figure 3. The different geometric positions of the SSAR antenna elements are the result of the moving platform in progress.
The Pulse Repetition Frequency (PRF) value of the radar system is the number of pulses that are transmitted per second, is shown in Figure 4 (Left), and the principle of SSAR operation is shown in Figure 4 (Right). Radar systems radiate each pulse at the carrier frequency during transmit time or Pulse Width (PW), wait for returning echoes during listening or rest time, and then radiate the next pulse, as shown in the above figure. The time between the beginning of one pulse and the start of the next pulse is already stated PRT and is equal to the reciprocal of PRF and is defined as follows:

$P R T=1 / P R F$

The surveillance radar system pulse repetition frequency determines its ability to unambiguously measure target range and range rate in a single coherent processing interval as well as determining the inherent clutter rejection capabilities of the radar system.

In order to obtain an unambiguous measurement of the target range, the interval between radar pulses must be greater than the time required for a single pulse to propagate to a target at a given range and back. The maximum unambiguous range $\left(R_{u n}\right)$ in relation to the velocity of electromagnetic propagation or speed of light $\left(c_{0}\right)$ is then given by the equation:

$R_{\text {un }}=c_{o} / 2 \cdot P R F=c_{o} \cdot P R T / 2$
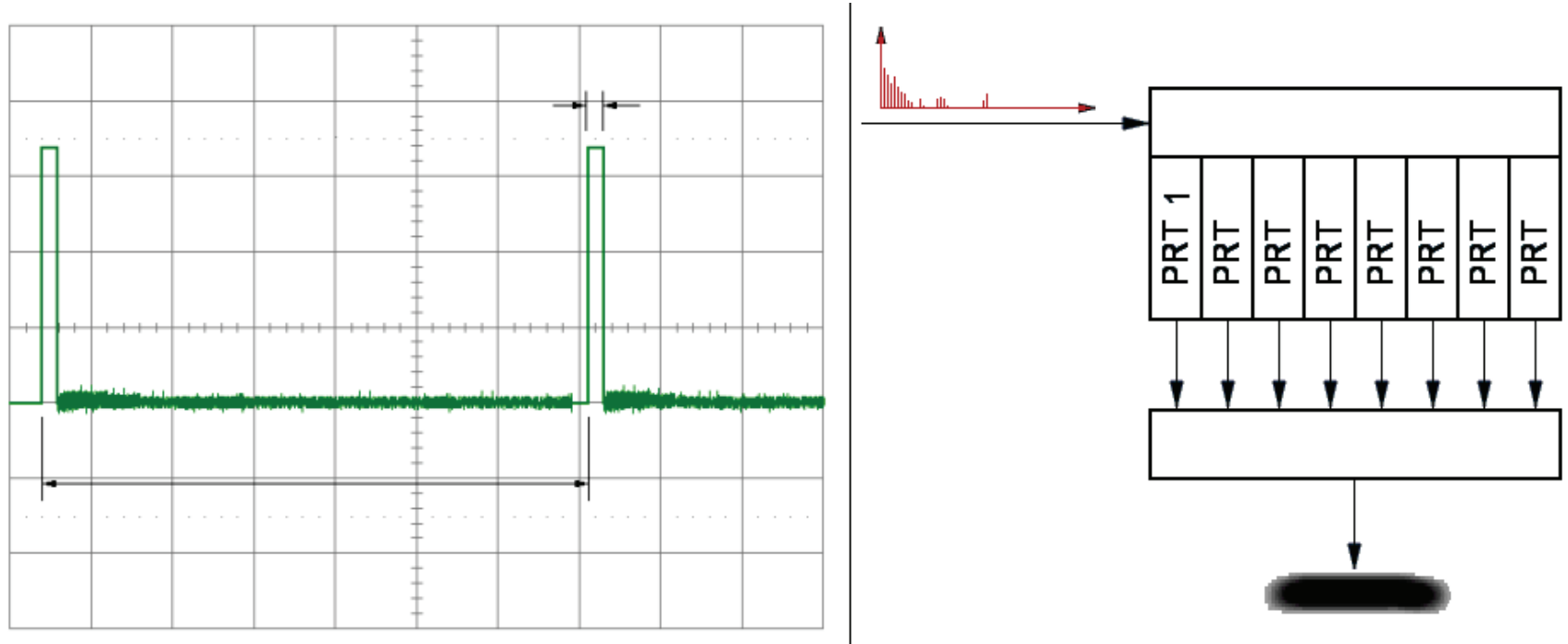

Figure 4

Value of PRF and Principle of SSAR Operation - Source: Wolff (2015). 
The SSAR processor stores all the radar returned signals, as amplitudes and phases, for the time period $(T)$ from position $A$ to $D$. Thus, now it is possible to reconstruct the signal that would have been obtained by the geometric length of the antenna $(L)$ with the following equation:

$L=v \cdot T=R_{o \lambda} / D \sin \theta_{o}$

where $\mathrm{v}=$ speed of the platform, $\mathrm{R}_{\circ}=$ slant range from the antenna to the midpoint of the swath, $\lambda=$ wavelength of the transmitted pulses (transmitted signal), $\mathrm{D}=$ distance, and $\theta_{\mathrm{o}}=$ look angle (Wolff, 2015; Chen 2014).

As the Line of Sight (LOS) direction changes along the space radar platform trajectory, a synthetic aperture is produced by signal processing that has the effect of lengthening the antenna. Presenting $T$ large makes the "synthetic aperture" enlarged and hence a higher resolution can be achieved. As a target (like a ship) first enters the radar antenna beam then the backscattered echoes from each transmitted pulse begin to be recorded. As the platform continues to move forward, all echoes from the target (ship) for each pulse are recorded during the entire time that it is within the beam. The point at which the target leaves the view of the radar beam sometime later determines the length of the simulated or synthesized antenna. The synthesized expanding beamwidth, combined with the increased time a target is within the array beam as ground range increases, balance each other, such that the resolution remains constant across the entire swath. The achievable azimuth resolution of an SSAR is approximately equal to one-half the length of the actual antenna and does not depend on platform altitude (distance).

The platform (aircraft or satellite) of a Side-Looking Airborne Radar (SLAR) travels forward in the flight direction with the nadir directly beneath the platform. The microwave beam is transmitted obliquely at right angles to the direction of flight illuminating a swath. Range refers to the across-track dimension perpendicular to the flight direction, while azimuth refers to the along-track dimension parallel to the flight direction. Swath width refers to the strip of the Earth's surface from which data are collected by side-looking airborne radar. It is the width of the imaged scene in the range dimension.

The longitudinal extent of the swath is defined by the motion of the aircraft with respect to the surface, whereas the swath width is measured perpendicularly to the longitudinal extent of the swath. The SLAR is a real aperture radar primarily, which requires a reasonable large antenna for adequately angular resolution. The azimuth resolution $\left(R_{a}\right)$ is defined as:

$R_{a}=H \cdot \lambda / L \cdot \cos \theta$ where $\mathrm{H}=$ height of the antenna (height of the spacecraft/ airplane), $\lambda=$ wavelength of the transmitted pulses, $L=$ geometric length of the antenna, and $\theta=$ incidence angle (Wolff, 2015; Ilcev, 2018).

The equation shows that with increasing altitude decreases the azimuthal resolution of SLAR and very long antenna (i.e., large $\mathrm{L}$ ) would be required to achieve a good resolution from a satellite. The SSAR system is used to acquire higher resolution. The size of the ground resolution cell increases on the side of the nadir as the distance between the radar platform and the ground resolution cell increases. This means that the ground resolution cells are larger towards the edge of the image than near the middle. This causes a scale distortion, which must be accounted for.

At all ranges, the radar antenna measures the radial line of sight distance between the radar and each target on the surface. This is the slant range distance. The ground range distance is the true horizontal distance with the ground corresponding to each point measured in the slant range. The cross-track resolution $\left(R_{r}\right)$ is defined as:

$R_{r}=c_{o} \cdot t_{p} / 2 \cos \theta$

where $c_{o}=$ speed of light and $t_{p}=$ pulse duration of the transmitter.

The practical example is given for the SLAR applications with the following characteristics: $\lambda=1 \mathrm{~cm}, \mathrm{~L}=3 \mathrm{~m}, \mathrm{H}=6000 \mathrm{~m}$, $\theta=60^{\circ}$ and $t_{p}=100 \mathrm{~ns}$. It has got a resolution of $R_{a}=40 \mathrm{~m}$ and $R_{r}=17.3 \mathrm{~m}$. The same SLAR on a platform in a height of $600 \mathrm{Km}$ would achieve an azimuth-resolution of $R_{a}=4000 \mathrm{~m}$.

The requirements of SSAR are: Stable, full-coherent transmitter, an efficient and powerful SSAR processor and exact knowledge of the flight path and the velocity of the platform. Using such a technique, radar designers, are able to achieve demanded resolutions, which would require real aperture antennas so large as to be impractical with arrays ranging in size up to $10 \mathrm{~m}$. The SSAR radar can be partnered by what is termed Inverse SAR (abbreviated to ISAR) technology, which in the broadest terms utilizes the movement of the target rather than the emitter to create the synthetic aperture. The ISAR radars have a significant role aboard maritime patrol aircraft to provide them with a radar image of sufficient quality that allows it to be used for target recognition purposes. The slant-range distortion occurs because the radar is measuring the distance to features in slant-range rather than the true horizontal distance along the ground. This results in a varying image scale, moving from near to far range.

The foreshortening of the SSAR system occurs when the radar beam reaches the base of a tall feature tilted towards the radar (e.g. a mountain) before it reaches the top. Because the 

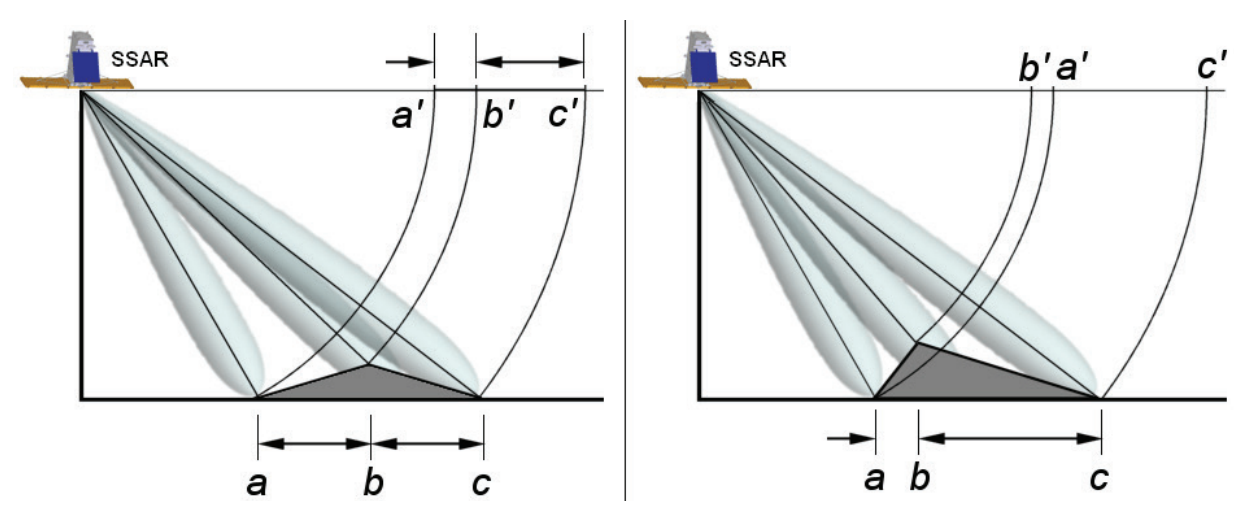

Figure 5.

SSAR Foreshortening and Layover - Source: Wolff (2015).

radar measures distance in slant-range, the slope (from point a to point (b) will appear compressed and the length of the slope will be represented incorrectly (a' to b') at the image plane, which system is shown in Figure 5 (Left).

Layover of the SSAR system occurs when the radar beam reaches the top of a tall feature (b) before it reaches the base (a). The return signal from the top of the feature will be received before the signal from the bottom. As a result, the top of the feature is displaced towards the radar from its true position on the ground, and "lays over" the base of the feature ( $b^{\prime}$ to $\left.a^{\prime}\right)$, shown in Figure 5 (Right) (Wolff, 2015, DLR, 2002)

3. Ships Surveillance and Detecting via SSAR TerraSAR-X Spacecraft

Ship surveillance and detecting is an important application of global Earth environment and surface monitoring for ecological, safety, and security purposes. In order to overcome the limitations by other systems, surveillance with SSAR is used because of its possibility to provide ship detecting at high resolution over wide swaths and in all weather conditions. During the last years, the demand for vessel surveillance has increased both for fisheries control and for maritime transport security and safety.

In order to overcome the limitations posed by conventional systems, surveillance with SSAR is being adopted more frequently because of its possibility to provide ship detecting over wide swaths and under many weather and environmental conditions. Up to now, different satellite sensors have been deployed for vessel surveillance, which additional availability in the future will be of great interest. Considering revisit and reliable coverage requirements of different SSAR operators, here is chosen and introduced TerraSAR-X (ScanSAR mode) onboard TerraSAR-X spacecraft, which gives a preliminary impression about its

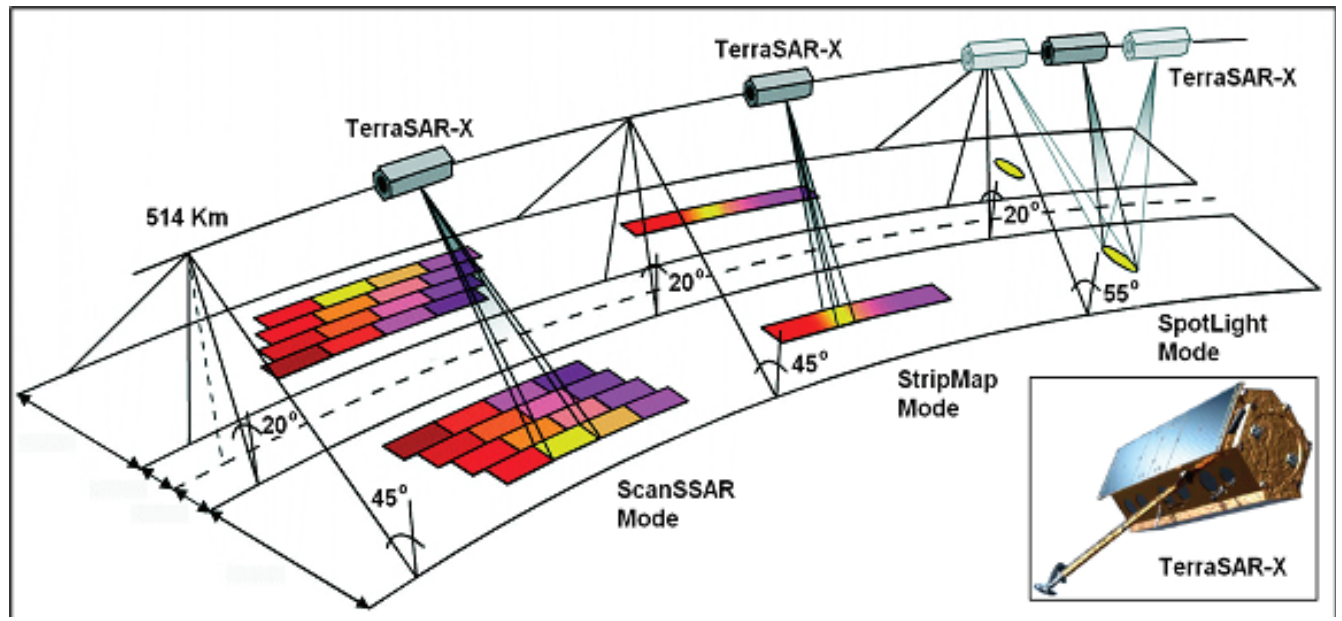

Figure 6 .

TerraSAR-X Spacecraft and Operational Parameters - Source: Airbus (2020). 


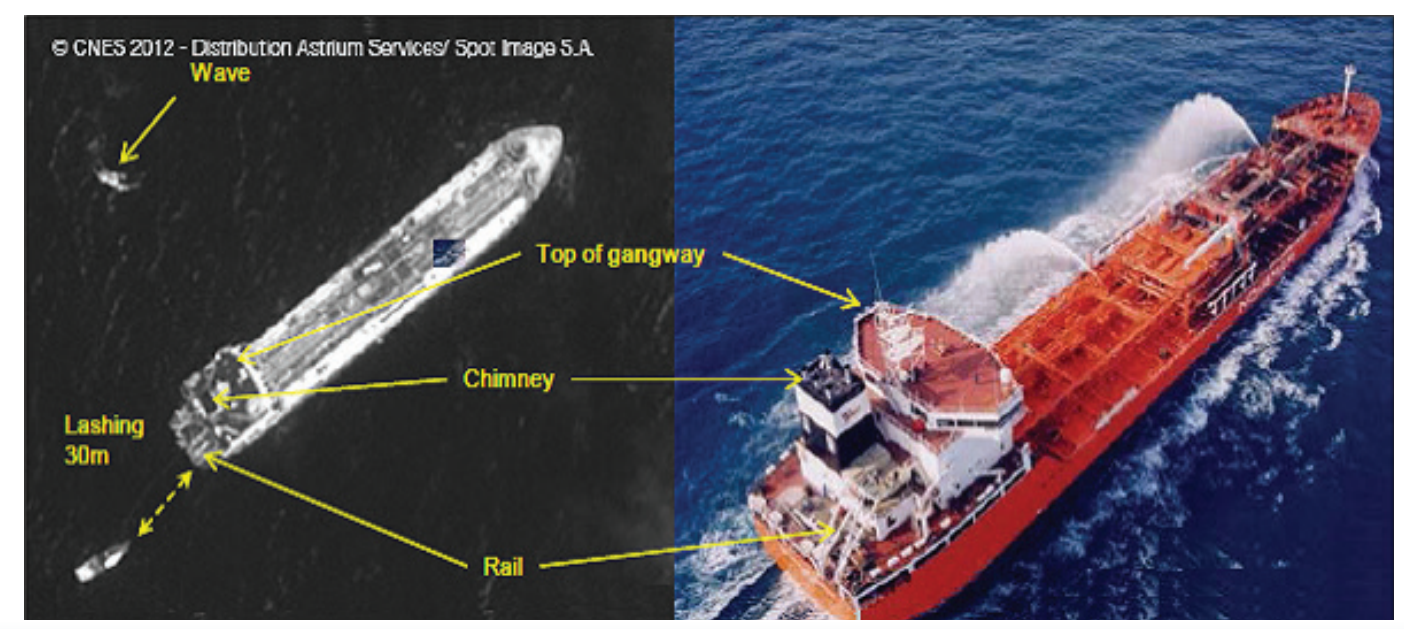

Figure 7.

Image of Captured Ship by Pirates - Source: Bosk (2014).

performance for vessel detecting and which includes the pirate boats activities and movements as well. The new X-band SSAR imager gives access to spatial resolution as fine as $1 \mathrm{~m}$, which orbital parameters with three scanning modes and TerraSAR-X satellite constellations are shown in Figure 6.

TerraSAR-X as a radar SSAR Earth observation satellite is a joint venture being carried out under a public-privatepartnership between the German Aerospace Center (DLR) and EADS Astrium provider. The exclusive commercial exploitation rights of TerraSAR-X are held by the geo-information service provider Astrium. TerraSAR-X was launched on 15 June 2007 and has been in operational service since January 2008. With its twin satellite TanDEM-X launched on 21 June 2010, so in such a way, TerraSAR-X (TS-X) acquires the data basis available from 2014.

The quality of TS-X images with respect to ship detecting is important together with the first assessment of its performance. Therefore, the velocity of a moving ship globally is estimated using complex TS- $\boldsymbol{X}$ data. As test cases, images were acquired over the North Sea, Baltic Sea, Atlantic Ocean, and the Pacific Ocean in Stripmap mode with a resolution of $3 \mathrm{~m}$ at the coverage of $30 \times 100 \mathrm{~km}$. With its active phased array X-band SSAR antenna (wavelength $31 \mathrm{~mm}$, frequency $9.6 \mathrm{GHz}$ ), TerraSAR-X acquires new high-quality radar images of the entire planet whilst circling Earth in a polar orbit at $514 \mathrm{~km}$ altitude.

The satellite orbit is selected such that the satellite flies in a sun-synchronous dusk-dawn orbit, which means that it moves along the day-night boundary of the Earth and always presents the same face to the Sun, ensuring an optimum energy supply via the solar cells. TerraSAR-X satellite is designed to carry out its task for five years, independent of weather conditions and illumination, and reliably provides radar images with a resolution of up to $1 \mathrm{~m}$.
Features of the TerraSAR-X satellite are: the resolution of up to $1 \mathrm{~m}$, excellent radiometric accuracy and geometric accuracy unrivaled by any other commercial spaceborne sensor, the quick site access time of 2.5 days maximum ( 2 days at $95 \%$ probability) to any point on Earth, unique agility (rapid switches between imaging modes and polarization). TerraSAR-X acquires radar data in the following three main imaging modes:

1. SpotLight provide up to $1 \mathrm{~m}$ resolution, scene size $10 \mathrm{~km}$ (width) x 5 km (length);

2. StripMap provides up to $3 \mathrm{~m}$ resolution, scene size $30 \mathrm{~km}$ (width) x 50 km (length); and

3. ScanSAR provides up to $18 \mathrm{~m}$ resolution, scene size $100 \mathrm{~km}$ (width) x $150 \mathrm{~km}$ (length).

However, StripMap and ScanSAR: acquisition length extendable to up to $1,650 \mathrm{~km}$.

In addition, the unique design of the TerraSAR-X's SSAR satellite antenna allows a variety of polarimetric combinations: single or dual polarization and even full polarimetric data take, are possible. Otherwise, depending on the desired application, one of four different product types (processing levels) can be selected: Single-look Slant-range Complex (SSC); Multi-look Ground-range Detected (MGD); Geocoded Ellipsoid Corrected (GEC), and Enhanced Ellipsoid Corrected (EEC).

TerraSAR-X will exhibit some technical-industrial novelties. One of these innovations is a kind of zoom shot, with the resolution and scanning field vice versa changeable in a 1:10 relationship, either a larger area to grasp or a small area with the highest possible resolution. Furthermore, the antenna can be aligned by electronics within an angle range so that the point of view is adjustable. Earlier radar satellites could radiate the antenna only in one direction. Except for other SSAR applications, 
TerraSAR-X serves for different purpose vessel tracking and detecting in normal situations and for anti-piracy activities.

Thus, identification of oil spills and leakages caused by vessels and also the characterization of typical drift behavior of icebergs in certain areas and times have a significant impact by using TerraSAR sensors and service. In Figure 7 is shown SSAR ship identification of hijacked by pirates Italian tanker m/t Enrico
Iveoli with Pleiades-1A in March 2012. The TerraSAR-X sensors can be employed for the identification of starting points of ships and destinations, typical traveling routes, contraband, smuggling and pirate activities (Airbus, 2020; Bosk, 2014).

In such a way, this ship is easily detected and identified by aid of TerraSAR-X SSAR with the following size characteristics at position: Latitude $=07^{\circ} 13^{\prime} 29^{\prime \prime} \mathrm{N}$. Longitude $=049^{\circ} 35^{\prime} 11^{\prime \prime} \mathrm{E}$, Length
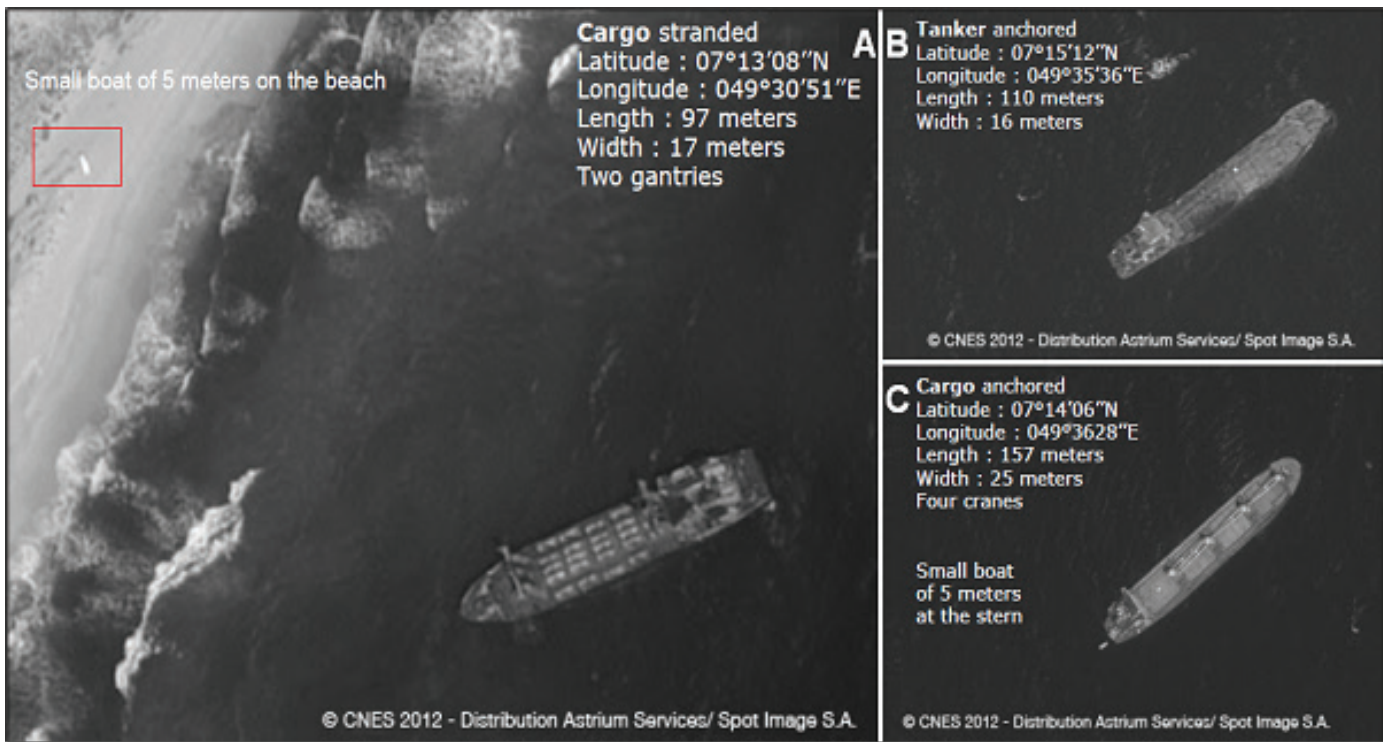

Figure 8.

Localization of other Ships in the area of m/t Enrico Iveoli - Source: Dearden (2020).

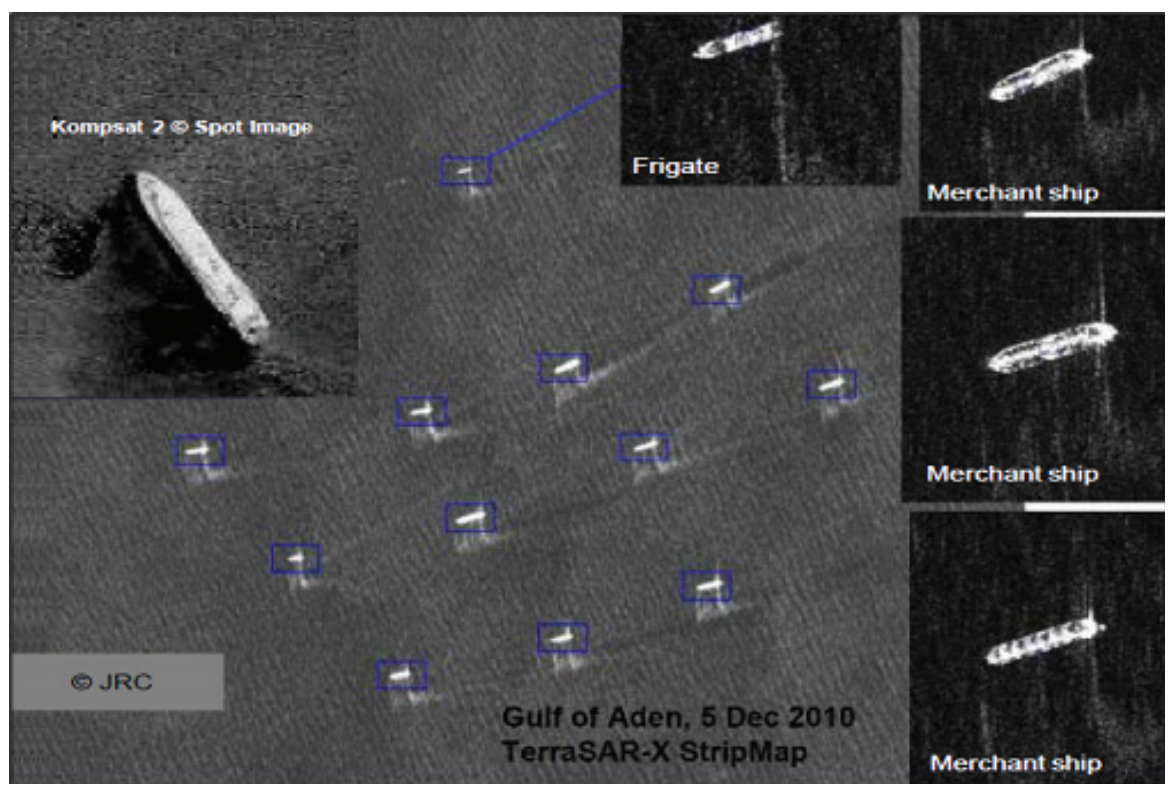

Figure 9.

Ships Tracking and Detecting Service - Source: Airbus (2020). 
$=138 \mathrm{~m}$, Width $=22 \mathrm{~m}$, Dhow $=17$ meters and Course $=053^{\circ}$. All these particulars are enough to find out and trace and assist the ship.

In Figure 8 is illustrated an example of localization of further vessels in the area of $\mathrm{m} / \mathrm{t}$ Enrico Iveoli for possible immediate assistance in SAR and to released activities.

Integrated Maritime Security and Safety Services provide a full range of information for enhanced security, safe shipping, and sustainable resources exploitation on a modular basis, benefiting from complementary capabilities of space SSAR sensors known

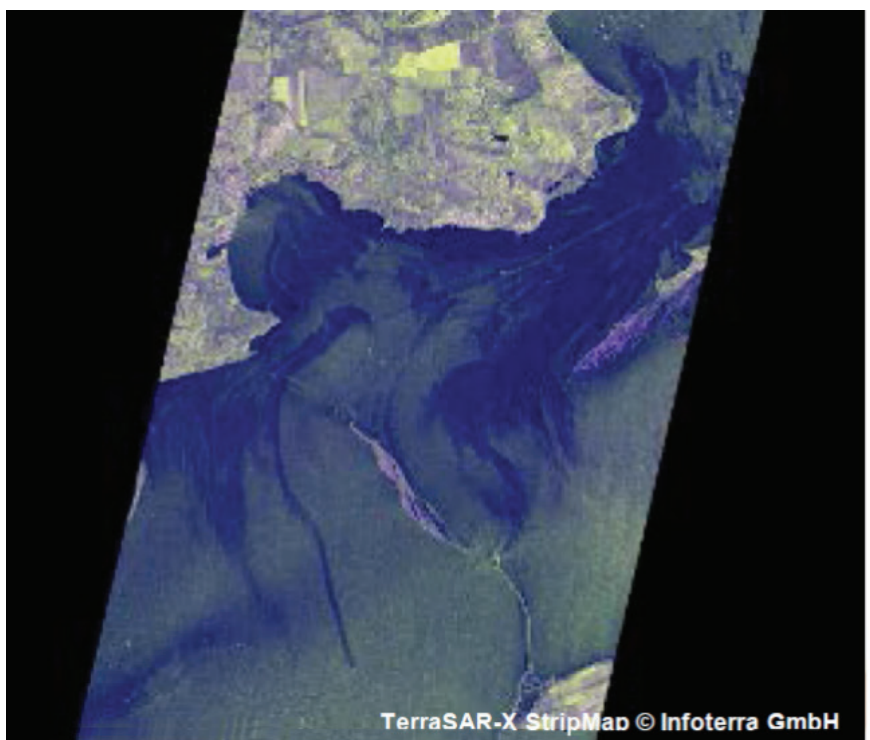

as: Ships Tracking and Detecting Service, Oil Spill Detecting Service, and Sea Ice Monitoring Service.

Traffic monitoring from space, day and night, from more than 500 kilometers up above are the service solutions for ships tracking and positioning, oil spill location and sea ice observation, as very important parameters for enhanced safety and security of ships. In Figure 9 is illustrated an example of ships tracking and detecting service via TerraSAR sensors in the Gulf of Aden as the hottest sea area in the world.

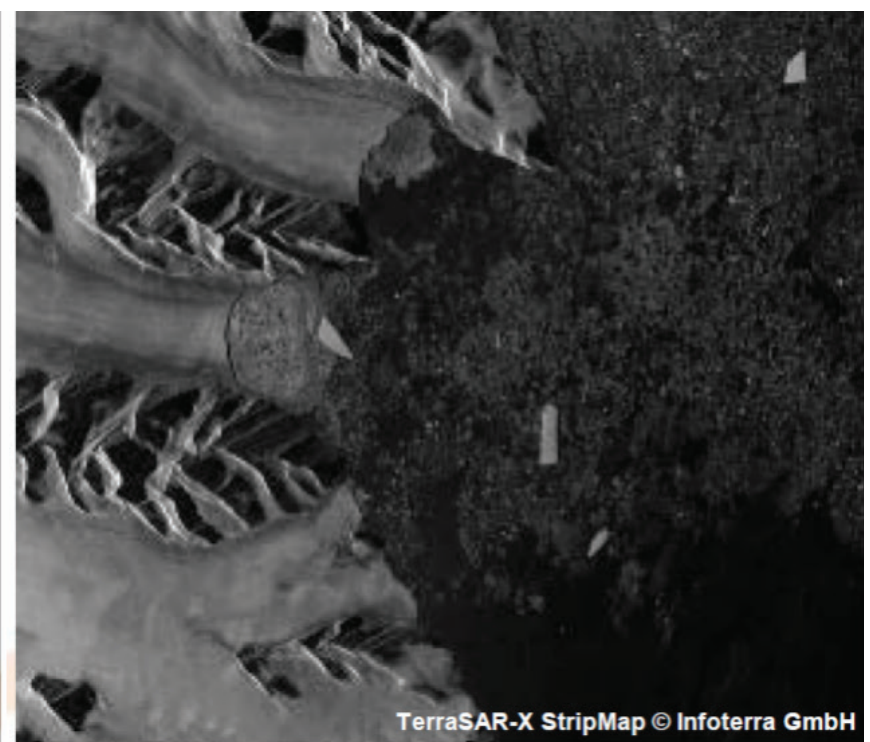

Figure 10.

Oil Spill Detecting and Sea Ice Monitoring Service - Source: Baltay (2010).

In Figure 10 (Left) is illustrated example of oil spill detecting service, and Figure 10 (Right) is illustrated example of sea ice monitoring service, both by aid of TerraSAR sensors for enhanced ecological and safety solutions at sea. The orbital parameters of TerraSAR-X spacecraft are: type of orbit circular, sun-synchronous and with orbit altitude of $514 \mathrm{Km}$, orbit period is $95 \mathrm{~min}$, the inclination angle is 97.40 , period repeat cycle is 11 days, imaging frequency in $95 \%$ cases -2 days, maximum - 4 days, and lifetime is 5 years (Airbus, 2020; Bosk, 2014; Dearden, 2020).

Therefore, TerraSAR sensors can be used for detecting of all kind of ships including small and non-metal boats (what Radar cannot provide), identification and detailed information gathering on identified suspicious vessels and pirate activities, such as images with the provision of high resolution: ship position, dimension, heading and even with R-AIS cooperativeness. Then, the system is providing accurate identification of oil spills, small scaled-leakages at oil rigs, and natural oil seeps. Finally, the important impact of the TerraSAR sensors is tactical support to ships and oil rigs operating in ice waters, which delivery detailed information on ice objects and conditions, route optimization and navigation safety of ships, enhanced coordination of ice breakers (ICEMAR project), and early warning and protection of oil rigs.

The TerraSAR-X spacecraft is equipped with an active synthetic aperture radar. Active in this context means that the beam can be aligned in a slewing range of 20 to 60 o. This is not done by mechanically moving the antenna or the complete satellite, but by superimposing many individual radar beams. The SSAR radar operated in the so-called $\mathrm{X}$-band spectrum. The radio signals emitted in this spectrum have a frequency of $9.65 \mathrm{GHz}$, which corresponds to a wavelength of about $3 \mathrm{~cm}$, thus allowing for such an extremely high image resolution.

With the adjustable angle radar sensor - along with other course refinements (precession by the Earth flattening) any place on Earth can be observed preferentially within 1-3 days. For a specific point on the equator, TerraSAR $X$ has a revisit cycle of 11 days. The revisit time decreases towards the poles, e.g. northern Europe has a revisit time of typically 3-4 days. 


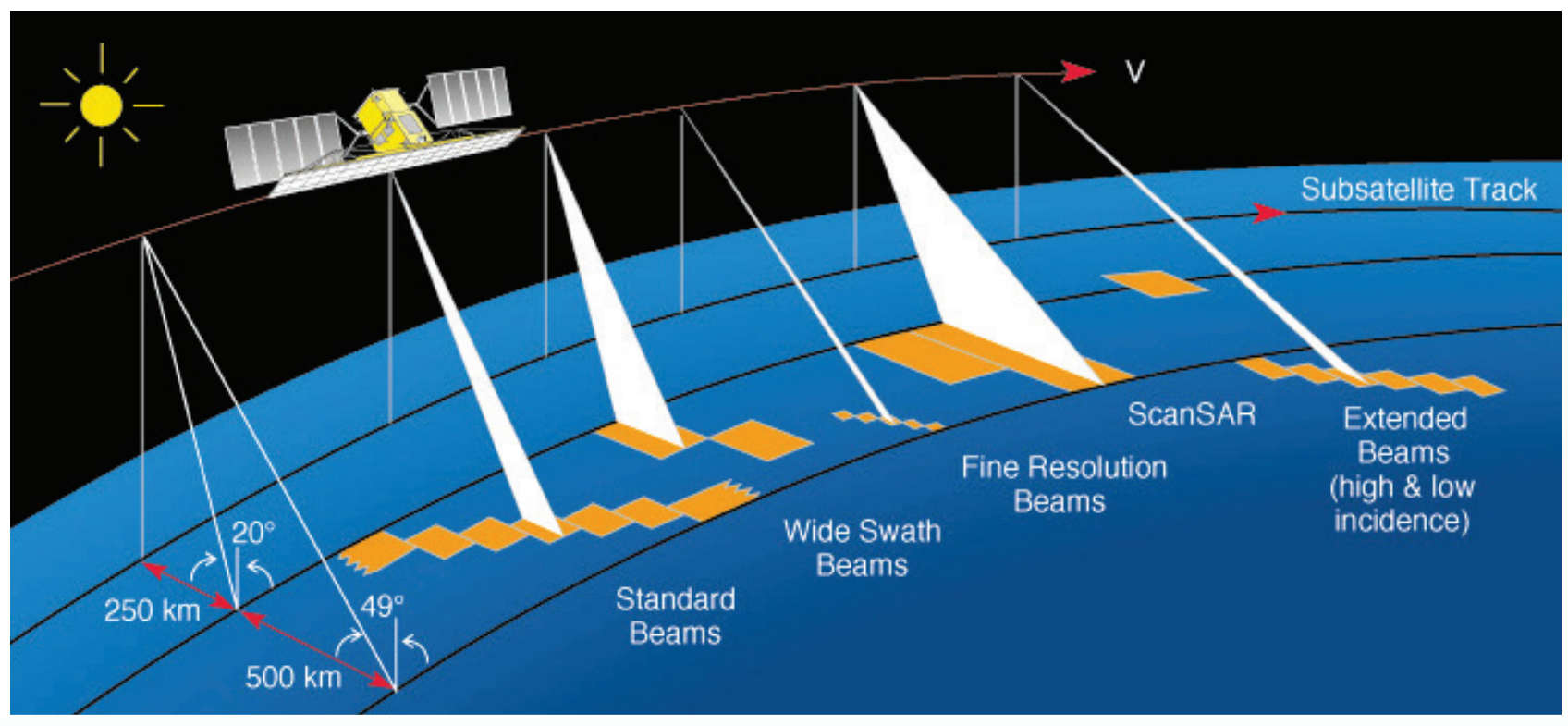

Figure 11.

Radarsat Spacecraft and Operational Parameters - Source: CSA (2020).

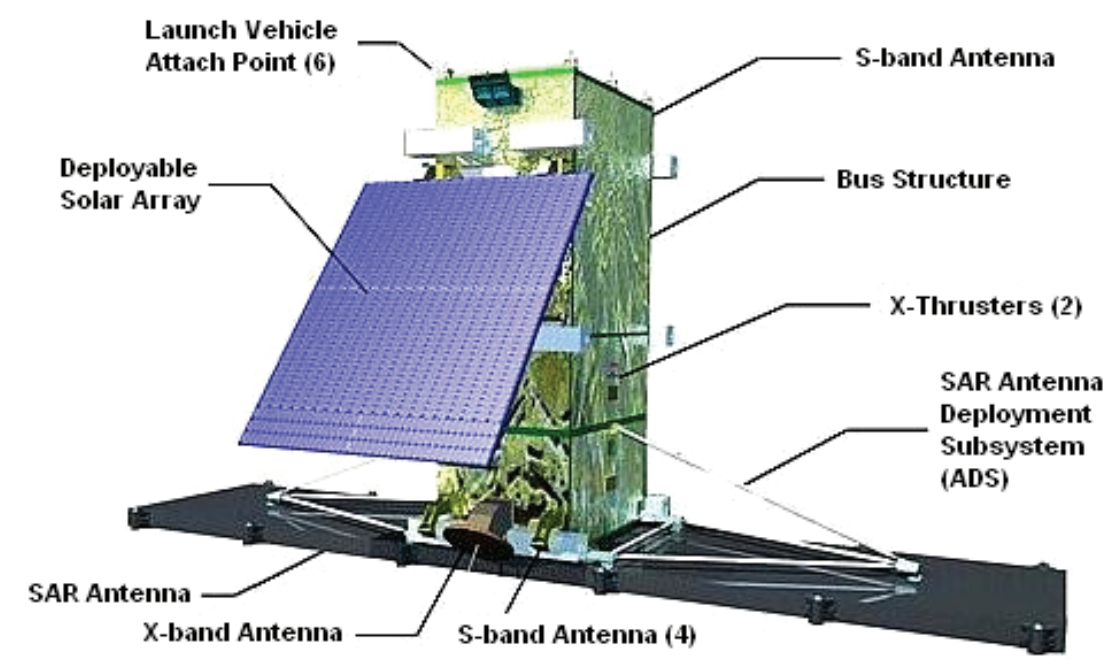

Figure 12.

Radarsat-2 Spacecraft - Source: ESA (2020).

The ground operating mechanism and controls for the TerraSAR X is developed by the DLR institute in Oberpfaffenhofen. It consists of mission operating equipment, payload ground segment with instrument operation, and calibration segment. At the base of the ground segment lies the German Space Operation Center (GSOC), the German Remote Sensing Datum Center (DFD) as well as Institutes for Methodology of Remote Sensing (MF) and the Institute for High-Frequency Engineering and Radar Systems
(HR) which are all part of the DLR (Baltay, 2010; CSA, 2020; ESA, 2020).

\section{SHIPS SURVEILLANCE AND DETECTING VIA SSAR RADARSAT SPACECRAFT}

The satellite Radarsat SSAR system is an innovative Earth observation satellite program developed by Canada to monitor 
Some Radarsat- 2 capabilities that benefit sea and river-ice applications are the multi-polarization options that improve ice-edge detecting, ice-type discrimination and ice topography and structure information. Earth observation satellites have an advantage over aerial surveillance, because clouds cannot affect SSAR surveillance.

2. Marine Surveillance - Worldwide offshore resourcebased operations such as fishing and oil and gas exploration and production have intensified over the past few decades. Thus, to monitor the world's oceans, Canada has provided radar data for operational applications such as ship detecting and tracking including pirate activities, oil spill monitoring at sea and wind and surface-wave field estimation. The Radarsat-2 SSAR sensors improves ship detecting and monitoring with its UltraFine beam mode using three-metre resolution and offers the potential for ship classification and enhanced safety. In addition, it can provide surveillance of pirate boats and captured ships by pirates. Government and industry require powerful solutions for assessing the resources and risks associated with the ocean environment.

The Canadian Space Agency (CSA) is currently conducting a feasibility study on the development of a C-band SAR satellite constellation referred to as Radarsat Constellation Mission (RCM). The current mission concept considers a three-satellite constellation that covers Canadian territory and waters on average once daily by combining ScanSAR data with a 50 resolution, acquired from ascending and descending orbits. The low-cost SSAR concept requires that the design of the SSAR system is in terms of mass, power consumption, volume, and antenna size in compliance with the constrains imposed by using a low-cost launch vehicle and a small satellite bus. In this regard, a two-panel deployable SSAR antenna was selected with the dimensions of $1.375 \mathrm{~m} \times 6.88 \mathrm{~m}$. Thus, full implementation of the constellation is planned for 2014/15. The challenge for maritime surveillance is to achieve wide-area SSAR data coverage at a resolution that suitable for ship detecting. Two principal imaging modes are considered: (1) a wide-area medium-resolution ScanSAR and (2) a high-resolution Stripmap mode.

The ScanSAR mode is designed to have a swath width of $350 \mathrm{Km}$ with a $500 \mathrm{Km}$ accessible region, shown in Figure 13 (Left). Using 4-looks in range and one look in azimuth, this ScanSAR mode provides a medium resolution of $50 \mathrm{~m}$. Thus, the trade-off is that 8 ScanSAR subbeams will be necessary to achieve the desired swath width. In this respect, however, other parameters are currently being analyzed, involving variations of the Noise Equivalent Sigma Zero (NESZ) and resolution across the swath. Regarding image quality assurance, there is a requirement on the ScanSAR beam to provide a mean NESZ of $-22 \mathrm{~dB}$ with an acceptable radiometric variation of $0.2 \mathrm{~dB}$ at the beam boundaries. Additionally, no nadir returns shall be visible in the ScanSAR image. The high-resolution Stripmap, shown in Figure 13 (Right) beam modes with a spatial resolution of $5 \mathrm{~m}$ and a swath width of $20 \mathrm{~km}$ is intended for specific on-demand image acquisitions. The RCM key system parameters or Radarsat- 2 are summarized in Table 1 (Kramer, 2002).

Table 1.

Key System Parameters of RCM.

\begin{tabular}{ll} 
Characteristics & Values \\
\hline Radar Frequesncy & C-band: $5.405 \mathrm{GHz}$ \\
\hline Chirp Bandwidth & $100 \mathrm{Mhz}$ \\
\hline Swath Width & $20-350 \mathrm{~km}$ \\
\hline Accessible Swath Width & $500 \mathrm{~km}$ \\
\hline Spatial Resolution (1-look) & $5-50 \mathrm{~m}$ \\
\hline Orbital Altitude & $\sim 500 \mathrm{~km}$ \\
\hline Imaging Time & 12 min per Orbit \\
\hline Repeat Orbit Circle & 12 Days \\
\hline Polarization & HH or Dual-pol (HH-VV) \\
\hline
\end{tabular}

Figure 14.

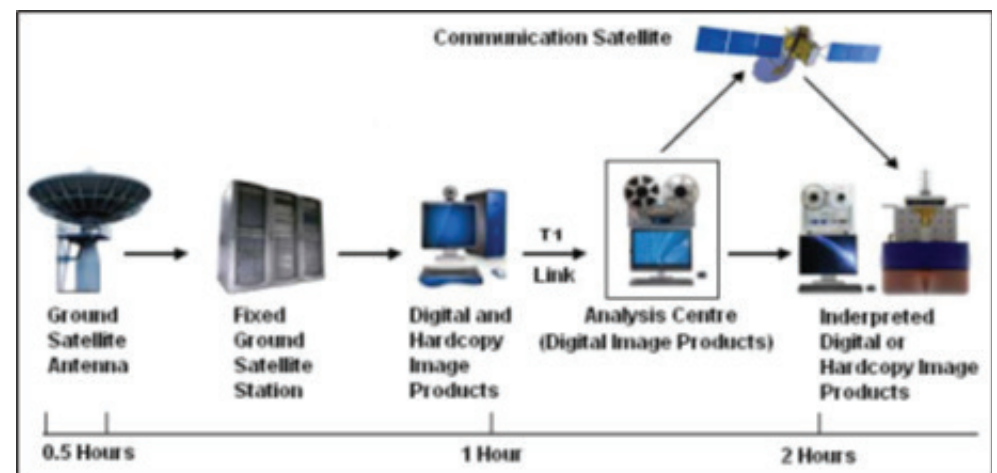

Radarsat Ground Segment and Processing Facilities - Source: Ilcev (2016). 
The Radarsat- 2 ground segment has been designed based on the need to support the advanced capabilities of the Radarsat-2 spacecraft, the need to support a commercial mission with increased data and order volumes, and the body of experience and lessons learned from the operation of the Radarsat-1 mission, which architectural design is illustrated in Figure 14. The design of the Radarsat- 2 network was produced in consultation with the key organizations and agencies that will be critical to the success of the mission. The ground segment is responsible for operating the Radarsat- 2 spacecraft, accepting and implementing orders, planning and tasking for image acquisition, product processing, distribution, and image quality control. In Figure 15 is depicted the Radarsat-2 spacecraft coverage map of ground stations (Ilcev, 2016).

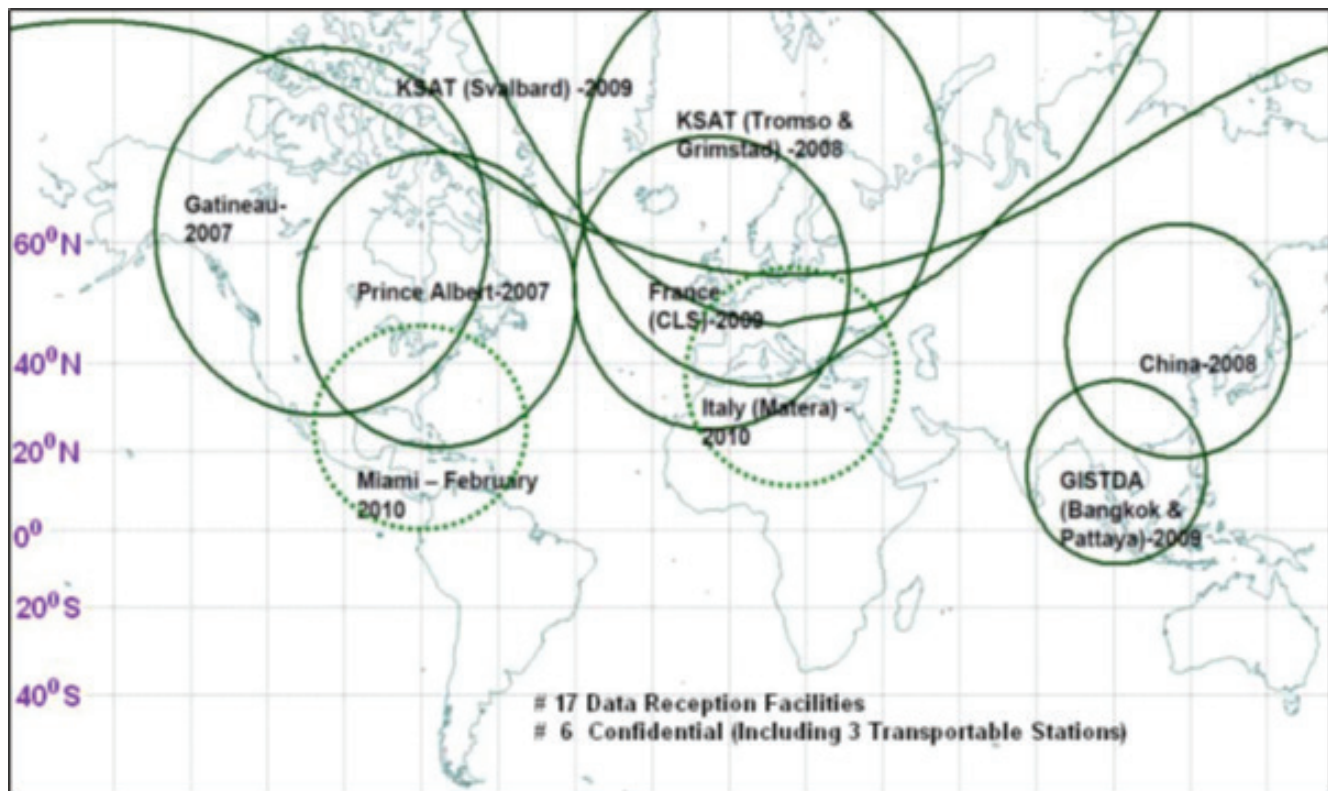

Figure 15.

Radarsat-2 Reception Coverage - Source: Ilcev (2018).

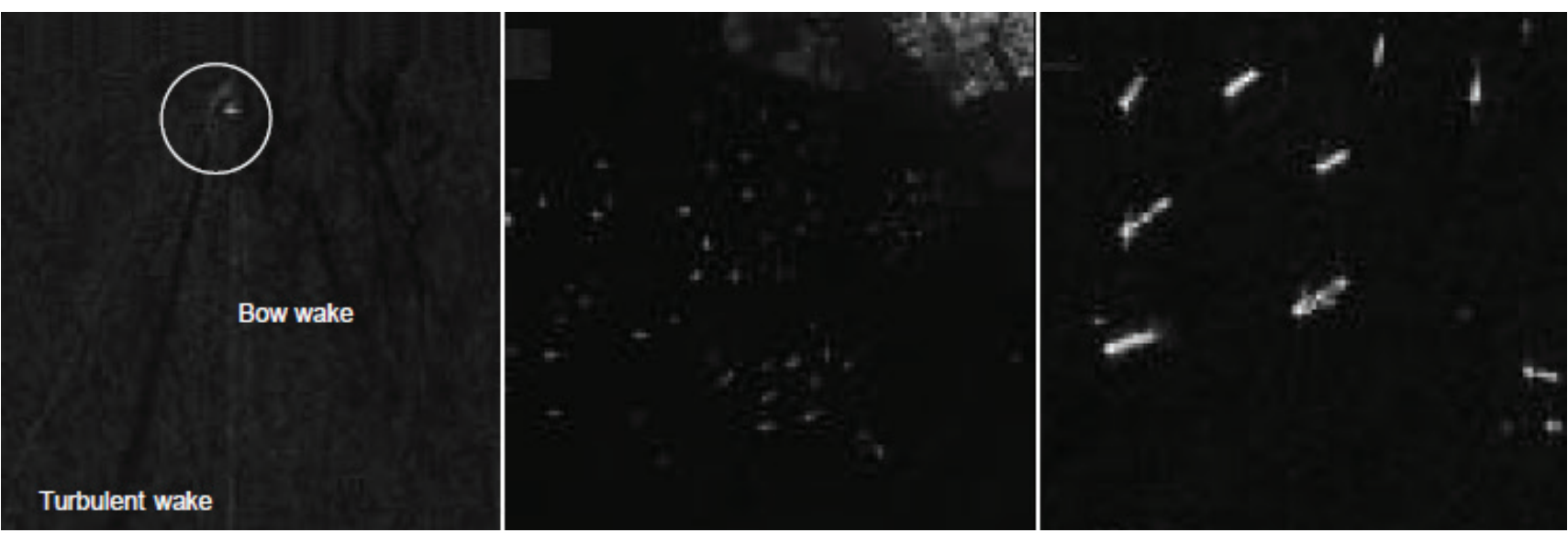

Figure 16.

Radarsat SAR Ships Monitoring and Detecting - Source: ESA (2020).

The ground support is provided for the addition of external network stations via a complete set of interfaces and the ability to reuse ground segment building block components. In Table 2 is presented comparison particulars of Radarsat- 1 and Radarsat-2 Spacecraft (Ilcev, 2018; ESA, 2020; Kramer, 2002). 
Table 2.

Comparison of Radarsat-1 and Radarsat-2 Spacecraft.
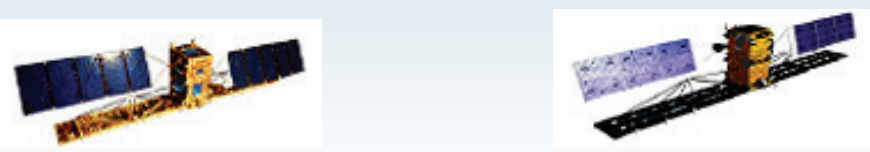

\begin{tabular}{lll}
\hline & RADARSAT-1 & RADARSAT-2 \\
\hline Launch & November 1995 & December 2007 \\
\hline Owner & Canadian Space Agency & MDA \\
\hline Design life & 5 years (now @ +14) & 7 years \\
\hline Imaging Frequency & C-Band; $5.3 \mathrm{GHz}$ & C-Band; $5.405 \mathrm{GHz}$ \\
\hline Spatial Resolution & 8 to 100 meters & 1 to 100 meters \\
\hline Beam Modes & 7 & 12 \\
\hline Polarization Channels & HH & HH, VV, HV, VH \\
\hline Look Direction & Right & Right and Left
\end{tabular}

In Figure 16 (Left) is shown detecting of ship wake and speed dome by Radarsat-1 sensors acquired on 28 February 1998 with a location in Arabian Gulf via beam in wide 2, resolution 27 $\mathrm{m}$ and bow wake scene size of $8.5 \times 8.5 \mathrm{Km}$. In Figure 16 (Middle) is illustrated image acquired also by Radarsat- 1 on 8 January 1996 in Singapore using beam fine 2 and resolutions $27 \mathrm{~m}$ and in Figure 16 (Right) is shown the same image in resolution of $8 \mathrm{~m}$. In Figure $17(A)$ is illustrated the SSAR image acquired by Radarsat-1 sensors on 20 February 1998 at 1929 UTC on C-band, HH ScanSAR wide $B$ indicating US trawler fleet vessels (circled) anchored under very low wind conditions in Dutch Harbor, Alaska. In such a way, all vessels are easy to detect since their large backscatter makes them stand out against the calm waters of the harbor.

However, outside the protection of the harbor where the wind is much higher and therefore the ship and sea contrast is reduced on the upper part of the image. In Figure 17 (B-Left) is shown image also acquired by Radarsat-1 on 5 July 2004 at 0411 UTC on C-band HH standard mode image showing small fishing vessels with approximately $10 \mathrm{~m}$ in length in the Egegik Bay salmon fishery in Bristol Bay, Alaska at position $58.2 \mathrm{~N}$ and

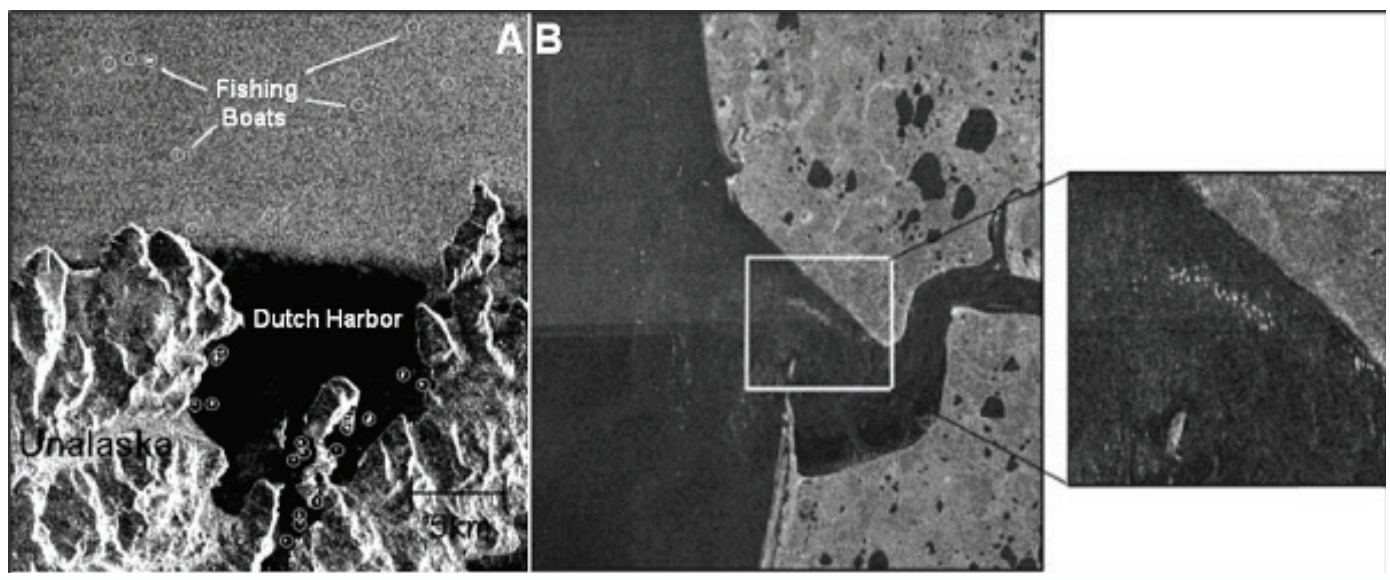

Figure 17.

Radarsat SSAR Fishing Vessels Monitoring and Detecting - Source: Pichel et al. (2005). 

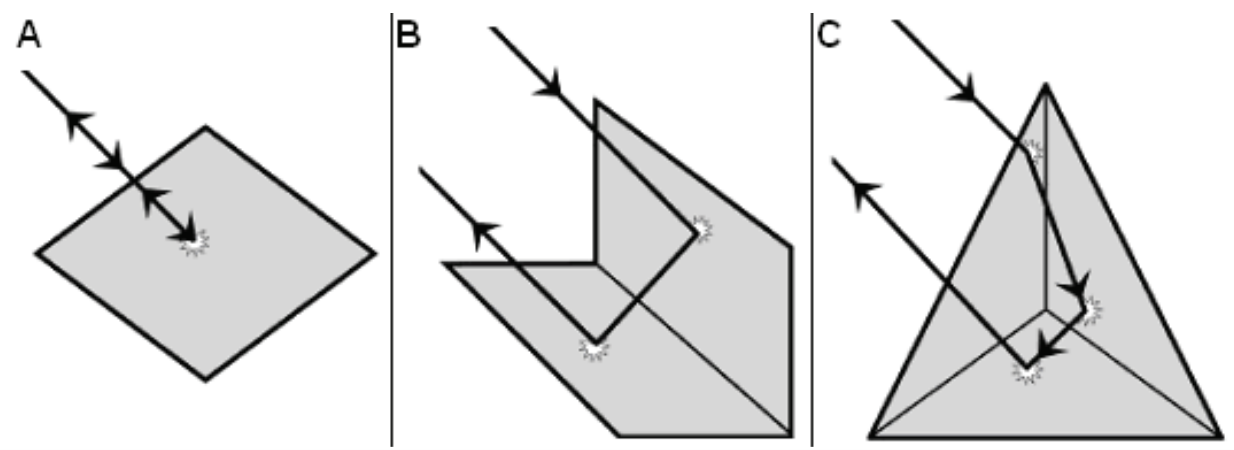

Figure 19.

SSAR Doppler and Phase History - Source: Pichel et al. (2005).

These waves travel at a known speed and the plunger is a source of waves analogous to those from radar. Observers are interested in the appearance of this wavefield at a certain distance, considering that ship is moving along the line. At position $B$, an operator on the ship would count the same wavenumber as emitted, since he is moving neither toward nor away from the waves (source). However, at position A, the ship is moving towards the waves and the operator will count a higher number of waves. The traveling speed of the waves is slightly increased by the speed of the ship. Thus, on the contrary, at position C, the ship is moving away from the buoy and the apparent frequency is lower, so the waves are moving in the same direction as the ship. Doppler frequency is the difference between received and emitted frequencies where the difference is caused by relative motion between the source and the observer.

Equivalently, the relative spacing between crests of the wavefield could be recorded along with the line AC, measured as if the wavefield were motionless. This leads to a phase model of the signals that is equivalent to the Doppler model. During the movement of the ship from position A to position C, the recording by the observer of the number of waves would look like the curve at the right of Figure 18. Instead of a plunger, let's now consider a spacecraft or aircraft emitting a radar signal. The ship corresponds to a target appearing to move through the antenna beam as the radar moves past. The record of the signals backscattered by the target and received would be similar to the record of the operator on the ship. Such a record is called the Doppler history (or phase history) of the returned signals. When the target is entering the beam, the Doppler shift is positive because the source to target distance is decreasing. The phase history is then stored to be used during the SSAR processing. By the time the antenna is abeam relative to the target, the received frequency is nominal, with the Doppler frequency being zero. Late it decreases as the satellite moves away and the phase history is then stored to be used during the SSAR processing.
The VDS service uses the detecting of ships from acquired SSAR imagery. The advantage of such a system is the all-weather and day or night vision capability as well as its noncooperative nature (meaning that vessels are imaged regardless of their actions). These features make VDS an ideal source of data to combine with other cooperative sources such as R-AIS, LRIT, and noncooperative VMS for its use in Maritime Surveillance and Fisheries Enforcement (ESA, 2020; Heng, 2012).

For realization of ships and wake detecting is important as follows:

1. SSAR Physical Process - Spaceborne instruments send out pulses of electromagnetic radiation and then measure the amplitude and phase of reflected radiation from the ocean, the land or man-made objects (referred to as hard targets such as ships and sea platform). Strong radar returns result from direct reflection from objects with high dielectric constant, namely conductors such as steel and even wood, oriented so that large surfaces are perpendicular to the incoming satellite radar beam or arranged in angular corner-shaped structures, namely corner reflectors. Corner reflectors have the property of returning radiation back to the source, parallel to its incoming direction. Ships constructions often contain superstructure or deck configurations that act as direct reflectors or corner reflectors. In addition, under the right orientation with respect to the satellite radar beam, the hull and ocean together can, through a double reflection, return significant energy back to the satellite SSAR antennas, which shapes are illustrated in Figure 19. Radar pulses from a satellite can be reflected back to the detector by: (A) direct reflection, e.g. from portions of the ship perpendicular to the radar beam, (B) a double bounce off a dihedral reflector, e.g. the ocean and then the ship or vice versa, or (C) a corner reflection (triple bounce) e.g. from the ship superstructure.

2. SSAR Imaging Characteristics - The direct radar return from a ship is the most common ship signature in SSAR imagery. Depending on the SSAR sensor resolution, the SSAR image 
signature of a ship direct return may simply be a single pixel with significantly greater normalized radar cross-section (i.e. large backscatter and therefore brighter) than surrounding pixels or, at a higher resolution (e.g. $30 \mathrm{~m}$ or better), an elongated series of brighter pixels. Thus, at the highest resolutions (10 m, $8 \mathrm{~m}$ or less), details of the ship superstructure may become distinguishable. As long as the ship has good radar backscatter characteristics, even ships smaller than the SSAR pixel resolution can be easily detected under a fairly wide range of wind and wave conditions (Pichel et al., 2005).
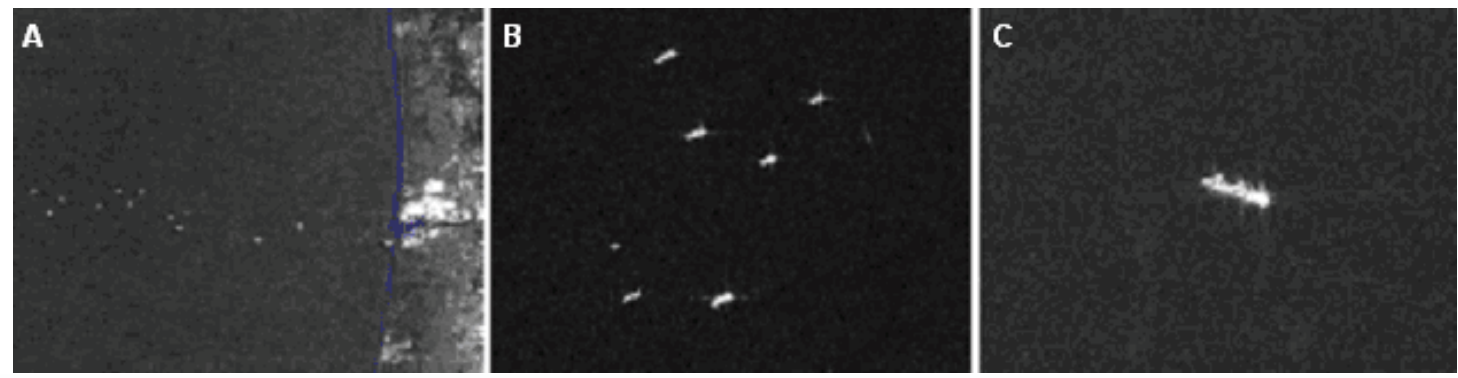

Figure 20.

SSAR 50, 25 and 8 m Resolutions of Ships Images - Source: Ilcev (2016).

The direct return from the ship is often the only ship signature, particularly (1) when the ship is not underway, (2) when higher winds or waves quickly destroy wake and slick signatures, or (3) when lower resolution modes, such as ScanSAR, are employed.

In Figure 20 are illustrated collections of ship direct return signatures. Automated ship detecting algorithms generally look for a statistically significant contrast between the ship and the local ocean background. However, a single detecting threshold cannot be used for the whole image since the background backscatter changes substantially with the SSAR angle of incidence, wind speed, and sea state. At this point, various algorithm approaches have been developed which automatically adapt to changing background backscatter during the search for targets.

Limitations to the success of direct detecting of ships and wakes with SSAR sensor systems can be grouped into the following five categories: (1) ship characteristics, (2) environmental conditions, (3) radar characteristics, (4) image quality, (5) image resolution and (6) wakes (Ilcev, 2016; Schott, 1997)

1. Ship Characteristics - Structural ship configuration with respect to the radar reflection, ship size, and structural material have a highly significant effect on the ability of SSAR systems to detect a particular vessel. In fact, a ship made from materials with high dielectric constant such as steel is a better radar reflector than a vessel made of non-conducting materials such as fiberglass or wood. A vessel with a substantial superstructure consisting of natural corner reflectors is a particularly good target. Also, a ship traveling perpendicular to the radar beam, in the same direction as the satellite is flying, generally, North or South presents as a larger target and has the possibility of a greater double reflection return.

\section{Environmental Conditions - Environmental} characteristics such as sea state, wind speed, proximity to land, and presence of ice affect the ability to distinguish SSAR ship signatures from the ocean background return. Thus, the greater the wind speed or the higher the waves, the greater the environmental contribution to the radar return signal, and thus the weaker the contrast between the vessel and the ocean background.

3. Radar Characteristics - Characteristics of the radar instrument (sensors) such as the angle of incidence (i.e. the angle between lines connecting the radar with the reflecting surface being viewed and the local normal to the surface), polarization, resolution, and sensitivity affect the ability to detect vessels with an SSAR system. The signal return from the ocean's surface is a function of angle of incidence with the return falling off as the angle of incidence increases. A ship return does not change as dramatically with the angle of incidence, but at higher angles of incidence, there is improved contrast between the ship and the ocean background.

4. Image Quality - The SSAR image processing errors and the inherent speckle noise in SSAR imagery can interfere with vessel detecting algorithms. The effect of speckle is noise in the image manifesting as random pixels that are much brighter or darker than the average of surrounding pixels. The speckle noise is a result of constructive or destructive interference during the coherent addition of backscatter from many different scatterers within a resolution cell of the SSAR image during the image integration time. Speckle noise in low-backscatter regions of an image where the surface return is below the noise floor of the SSAR instrument can appear as small vessels to a ship-detecting algorithm. The speckle noise of an SSAR image will also ultimately limit the minimum vessel size that can be detected since smaller vessels will become indistinguishable from speckle. Processing 


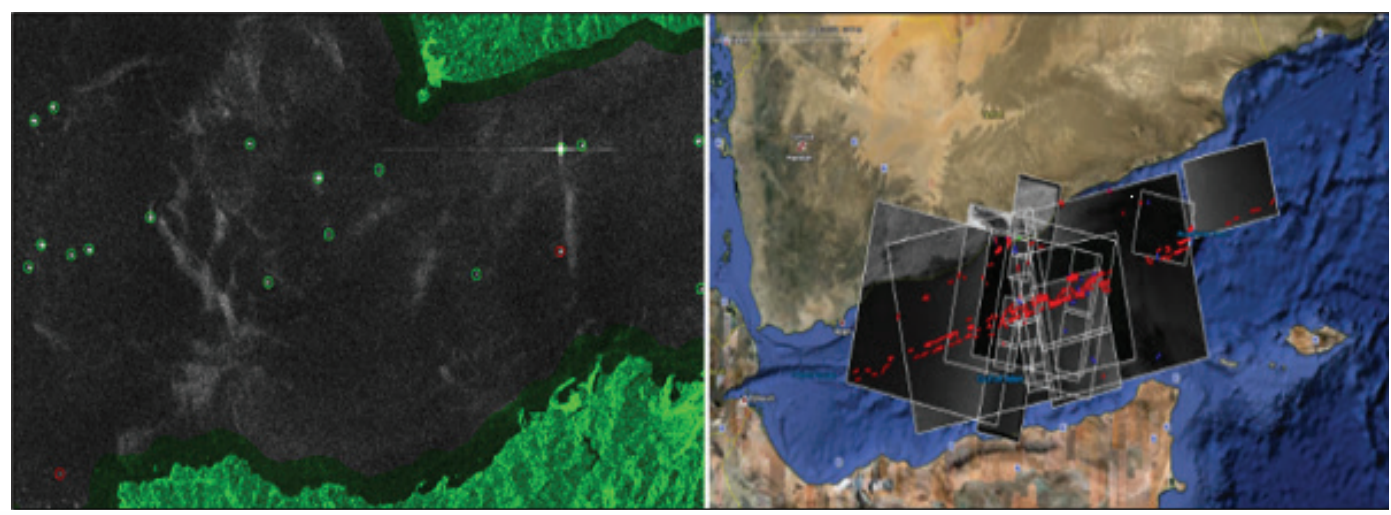

Figure 21.

SSAR Identification of Suspicious and Pirated Vessels - Source: Ilcev (2016).

problems such as obvious seam boundaries between beams in ScanSAR imagery, nadir ambiguities (an along-track bright-line resulting from the timing of the direct return from the Earth surface immediately below the satellite), scalloping in ScanSAR imagery (a cyclic banding pattern caused by errors in Doppler processing) and cross-track noise lines caused by processing errors can all be problematic, mainly by masking hardship targets within erroneous high backscatter anomalies. It should be noted that these processing problems are processor dependent on different SSAR processors will produce slightly different SSAR images when attempting to handle difficulties encountered during processing. Finally, image Earth location errors can interfere with the correct discrimination between small coastal islands and coastal vessels.

5. Image Resolution - Although all the different modes (specific resolution and swath width characteristics) of available satellite SSAR imagery are useful for detecting of ships, particularly larger ships, some modes are better than others. The highest resolution of radar images is $1 \mathrm{~m}$ and going up to weakest one as 10 m (Ulaby et al., 2014; Chuvieco and Huete, 2009).

6. Wakes - The track left in the water by a moving vessel, the wake, is an important clue in the detecting of ships. Wake structures fall into four categories: (1) turbulent wakes stretched out directly behind the vessel, (2) Kelvin wake formed by decameter-scale surface gravity waves generated by the passage of the vessel and propagating outward from the vessel track, (3) narrow-V wakes visible through Bragg scattering from short centimeter-scale waves generated by hydrodynamic processes along the ship's hull, and (4) internal wave wakes generated under conditions of shallow stratification.

As new SSAR satellites are becoming available, the VDS solutions should evolve in order to cope with the enhanced capabilities of the sensors, especially higher resolution. Namely, the intention of VDS developments and improvements is VDS evolution in higher resolution of images, which will be used for enhanced tracking and detecting of vessels. In Figure 20 is shown that three SSAR images with a resolution of $50 \mathrm{~m}(\mathrm{~A}), 25 \mathrm{~m}(\mathrm{~B})$, and $8 \mathrm{~m}(\mathrm{C})$. Namely, as resolution increases new details from the vessels are revealed.

The significant tracking and detecting at sea is identification and flagging of Suspicious Vessels from SSAR imagery in integration and correlation with other similar systems such as R-AIS/Satellite and AIS/LRIT/VMS data. This tracking and detecting integration is shown in Figure 21 (Left), which illustrate the image of all ships passing in the area of Gibraltar.

Satellite acquired SSAR vessel detecting (VDS) provides the position of vessel targets during the image acquisition time. In such a way, these vessels position can be confirmed by other systems, so if some image of the ship is not matching with shore data means that is suspicious. In most cases, it is impossible to identify the vessel from its SSAR signature therefore fusion with other positional data (namely R-AIS, LRIT, VMS tracks) is essential, which integration system for anti-pirate actions is shown in Figure 21 (Right).

Therefore, correlation methodologies use the prediction of the position at the time of the image together with the size information (obtained from both registry and radar signature) to find the best match and make possible the identification of the vessels on the image and flagging of suspicious vessels (Ilcev, 2016; Baltay, 2010).

\section{CONCLUSION}

In this paper is proposed the space remote sensing and detecting systems of the oceangoing ships as an alternative to current applications used in the maritime transportation industry. Thus, ships detection from space SSAR imagery system is an operational application that can be performed in near-real space and time, with detection real and false alarm rates that are sufficient for some users and scenarios that need to be improved 
for shipping service. The values of the SSAR system for vessel tracking can be only reached when their detection data, as an alternative, is integrated with the current vessel data tracking from other sources, and especially for detecting ships in a distress situations. Although the SSAR data imaginary system for maritime applications is increasingly being done, classification of the vessel from SSAR data is still difficult and automatic algorithms do not yet always provide a reliable size of estimates.

Accordingly, researchers and developers of the SSAR tracking data system have to enhance integration parts of space and ground segments as new shipborne project and to improve their subsystems and products. Although detection of oceangoing ships from SSAR images can be hindered by clouds or poor illuminations, using accurate sensing techniques during favorable observation conditions gives very good and valuable results. Therefore, to obtain optimal or even desirable space remote surveillance and observational results an automatic shipping surveillance system should combine data from a number of different sensors. In fact, the SSAR space imagery, which is unaffected by cloud cover or illumination, would be used as complementary solutions. Demanding applications will enable it to be combined with the increased availability of space systems under operationally and commercially attractive conditions.

\section{REFERENCES}

Airbus, 2020. TerraSAR-X Image Product Guide, Airbus Defence and Space.

Baltay S., 2010. Astrium Services Solutions for Risks and Crises Management, Infoterra, Farnborough, UK.

Baltay, S., 2010. Astrium Services Solutions for Risks and Crises Management, Infoterra, Farnborough, UK.

Bosc, P.-A., 2014. Earth Observation for Security and Dual Use. Handbook of Space Security, pp.555-579. Available at:

http://dx.doi.org/10.1007/978-1-4614-2029-3_7.
Chen, H.S., 2014. Space Remote Sensing Systems, Academic Press, Washington DC.

Chuvieco, E., 2009. Fundamentals of Satellite Remote Sensing. Available at: http://dx.doi.org/10.1201/b18954.

CSA, 2020. Components and Specifications, Canadian Space Agency, Quebec, Canada.

Dearden, L., 2020. Daily Press and Media Panorama with Maritime Thematic, GeoGarage Blog.

DLR, 2002. TerraSAR-X (TSX) Mission, German Aerospace Centre, Cologne, Germany ESA, 2020. RADARSAT Constellation Mission (RCM), Paris, France.

ESA, 2020. Synthetic Aperture Radar (SAR), Earth Online, European Space Agency, Paris, France.

Heng, O., 2012. An Introduction to Contemporary Remote Sensing, McGraw-Hill, New York.

Ilcev, D.S., 2016. Global Satellite Ship Tracking and Surveillance Systems, DUT, Durban, South Africa.

Ilčev, D.S., 2018. Global Satellite Meteorological Observation (GSMO) Theory. Available at:

http://dx.doi.org/10.1007/978-3-319-67119-2.

Kramer, H.J., 2002. Earth Observation/Monitoring Missions. Observation of the Earth and Its Environment, pp.329-553. Available at: http://dx.doi.org/10.1007/978-3-642-56294-5_5.

Pichel, W.G. et al., 2005. Ship and Wake Detection, Chapter 12, Office of Research and Applications, NOAA/NESDIS, Camp Springs, USA.

Richards, J.A., 2009. Remote Sensing with Imaging Radar, Springer, Boston. Schott, J.R., 1997. Remote Sensing, Oxford University Press, Oxford.

Ulaby, F. \& Long, D., 2014. Microwave Radar and Radiometric Remote Sensing. Available at:

http://dx.doi.org/10.3998/0472119356.

Wolff, C., 2015. Synthetic Aperture Radar - Radartutorial, Cologne, Germany. 